\title{
Experimental Studies of Heat Transfer Characteristics and Properties of the Cross-Flow Pipe Flow Melt Lead
}

\author{
Alexandr Viktorovich Beznosov, Mikhail Vladimirovich Yarmonov, \\ Artyom Dmitrievich Zudin, Alexey Sergeevich Chernysh, Olga Olegovna Novogilova, \\ Tatyana Alexsandrovna Bokova \\ Nizhny Novgorod State Technical University, Nizhny Novgorod, Russia \\ Email: ats@nntu.nnov.ru
}

Received 23 September 2014; revised 20 October 2014; accepted 17 November 2014

Copyright (C) 2014 by authors and Scientific Research Publishing Inc.

This work is licensed under the Creative Commons Attribution International License (CC BY). http://creativecommons.org/licenses/by/4.0/

(c) (i) Open Access

\section{Abstract}

The process of heat transfer in a HLMC cross-flow around heat-transfer tubes is not yet thoroughly studied. Therefore, it is of great interest to carry out experimental studies for determining the heat transfer characteristics in a lead coolant cross-flow around tubes. It is also interesting to explore the velocity and temperature fields in a HLMC flow. To achieve this goal, experts of the NNSTU performed the work aimed at the experimental determination of the temperature and velocity fields in high-temperature lead coolant cross-flows around a tube bundle. The experimental studies were carried out in a specially designed high-temperature liquid-metal facility. The experimental facility is a combination of two high-temperature liquid-metal setups, i.e., FT-2 with a lead coolant and FT-1 with a lead-bismuth coolant, united by an experimental site. The experimental site is a model of the steam generator of the BREST-300 reactor facility. The heat-transfer surface is an in-line tube bank of a diameter of $17 \times 3.5 \mathrm{~mm}$, which is made of 10H9NSMFB ferriticmartensitic steel. The temperature of the heat-transfer surface is measured with thermocouples of a diameter of $1 \mathrm{~mm}$ being installed in the walls of heat-transfer tubes. The velocity and temperature fields in a high-temperature HLMC flow are measured with special sensors installed in the flow cross section between the rows of heat-transfer tubes. The characteristics of heat transfer and velocity fields in a lead coolant flow were studied in different directions of the coolant flow: The vertical ("top-down" and "bottom-up") and the horizontal ones. The studies were conducted under the following operating conditions: The temperature of lead was $t=450^{\circ} \mathrm{C}-5000^{\circ} \mathrm{C}$, the thermodynamic activity of oxygen was a $=10^{-5}-10^{\circ}$, and the lead flow through the experimental site was $Q=3-6 \mathrm{~m}^{3} / \mathrm{h}$, which corresponds to coolant velocities of $V=0.4-0.8 \mathrm{~m} / \mathrm{s}$. Comprehensive experimental studies of the characteristics of heat transfer in a lead coolant cross-flow around tubes have been carried out for the first time and the dependences for a controlled and regulated content of the thermodynamically active oxygen impurity and sediments of impurities have been 
obtained. The effect of the oxygen impurity content in the coolant and characteristics of protective oxide coatings on the temperature and velocity fields in a lead coolant flow is revealed. This is because the presence of oxygen in the coolant and oxide coatings on the surface, which restrict the liquid-metal flow, leads to a change in the characteristics of the wall-adjacent region. The obtained experimental data on the distribution of the velocity and temperature fields in a HLMC flow permit studying the heat-transfer processes and, on this basis, creating program codes for engineering calculations of HLMC flows around heat-transfer surfaces.

\section{Keywords}

Heavy Liquid-Metal Coolant, Lead, Lead-Bismuth, Fast Neutron Reactors, Heat-Exchange, Wall Boundary Area

\section{Introduction}

It is not possible to obtain a package of data required to design heat-exchange equipment operating in a lead coolant medium only by means of a calculation based on the outcome of theoretical design models. All theoretical models are bound to introduce simplifications that do not reflect reality. For instance, an expression for calculating heat-exchange coefficients usually introduces the values of coolant mean velocities, wall temperature, characteristics of the fluid itself and its flow. A heat-exchange coefficient is a more complicated function of a larger number of variables conditioning the heat-exchange process. Under otherwise equal conditions, it is dependent on the size of heat-exchange surface elements (objects with similar heat-exchange surface geometry, but which are of smaller size, have greater heat-exchange coefficients since these objects have boundary layers of lesser thicknesses), the heat flow direction (at transfer of heat from the coolant to the wall, the heat-exchange coefficient is higher than that at flow-around of the inner wall of a pipe of the same diameter), the wall boundary layer effect, the heat flow direction (at transfer from the coolant to the wall, the heat-exchange coefficient is higher than that at transfer of heat from the wall to the coolant) and other, which has a material effect on the heat-exchange characteristics.

This paper contains the results of an analysis and experimental research for determining heat-exchange characteristics in a heat-removing experimental section at crossflow of an in-line heat-exchange tube bank simulating lead-to-wall heat-exchange conditions within the range of operating parameters of the loop of a projected reactor installation of BREST type under a controlled and regulated content of oxygen impurity in the coolant and loop, as well as at the supply to the loop of a lead coolant of gas-air mixtures, which simulates potential malfunction during the emergency "Interloop Leakiness of Steam Generator".

\section{Relevance}

At the present time, specialists in the Russian Federation are engaged in designing fast neutron reactor installations cooled by lead and lead-bismuth coolants (heavy liquid-metal coolants); developments of such reactor installations are also under way in other countries. Previously, the NNSTU conducted research of heat-exchange characteristics in heavy liquid-metal coolants under conditions of longitudinal flow of heat-transfer tubes [1]-[3].

One of the relevant thermophysical tasks is to obtain experimental and theoretical data on the heat-exchange of a lead coolant at crossflow of a tube bank and under regulated content of oxygen impurity in the reactor coolant as well as to specify criterial dependencies of the heat-exchange based on the operational content of impurities in the coolant, including processing treatments of the loop.

\section{Work Objective}

The purpose of this work is to carry out experimental research of heat-exchange characteristics, temperature and velocity fields in high-temperature lead coolant flows within an in-line heat-exchange tube bank under control and regulation of the oxygen impurity content in the coolant. The experimental research was conducted on a specially fabricated test bench comprising an experimental thermophysical assembly with a transversely streamlined heat-exchange surface. Previously, the NNSTU had conducted experiments with lifting lead crossflow 
around pipes [4]. This work is a continued activity of the test cycles, and it reflects the testing results at downward and horizontal flows of lead.

\section{Description of Test Facility}

The consolidated FT-2B test bench represents a combination of two high-temperature liquid-metal benchesFT-2 with a lead coolant and FT-1 with a lead-bismuth coolant.

The bench includes liquid-metal pumps, buffer tanks, gage tanks, filling, treatment and draining systems, a gaseous system and a test section. The equipment and pipelines coming in contact with lead and lead-bismuth coolants are made of steel of 08X18H10T type, are electrically heated and heat-insulated. The volume of the lead coolant in the loop is approximately $0.12 \mathrm{~m}^{3}$, and the volume of the lead-bismuth coolant in the loop is approximately $0.6 \mathrm{~m}^{3}$. The lead and lead-bismuth flow rates are controlled by magnetic flow meters periodically calibrated by the gage tanks. The oxygen content in the coolant is controlled by transducers of oxygen thermodynamic activity in the alloy. Variation of the electrically-insulating coating performance is achieved by processing the coolant with gaseous mixtures with hydrogen or oxygen. Heat removal in the test section for the purposes of expanding the temperature measurement range is performed using a eutectic lead-bismuth alloy supplied from the FT-1 bench. This technical solution makes it possible to carry out research of lead-to-wall heat-exchange without using any high-pressure water circuit. The lead cooled down in the test section is warmed up by a tubular electric heater.

The experimental model (Figure 1) represents a heat-exchange surface made in the form of an in-line bank of horizontal heat-transferring tubes $17 \times 3 \mathrm{~mm}$ in diameter and made of ferrite-martensitic steel 10X9HSMFB, which corresponds to the steam generator tube material in the BREST Steam Generating Reactor Installation Project. The tube bank consists of six longitudinal and three transverse runs of tubes, where the first and the third transverse runs represent simulators of the heat-transferring tubes made in the form of slit tubes placed on the inner surface of the test section housing. The longitudinal and transverse relative tube pitches are equal to 1.47. In the steam generator project, the tube package winding angle is $9^{\circ}$, and in this model, a horizontal configuration of the heat-transferring tubes is accepted, which makes a margin during thermohydraulic calculations as far as the lead coolant is concerned.

Due to a short length of the heat-transferring tubes, which is $100 \mathrm{~mm}$, there is no spacer grid available. Spacing is provided by a delivery and collecting manifolds, into which the heat-transferring tubes are embedded. The heat-exchanger shell is a capacity made in the form of a rectangular-sectioned channel, which contributes to a significant reduction of the test section passage area and, consequently, to an increase in the lead coolant slip velocity in the heat-transferring tubes.

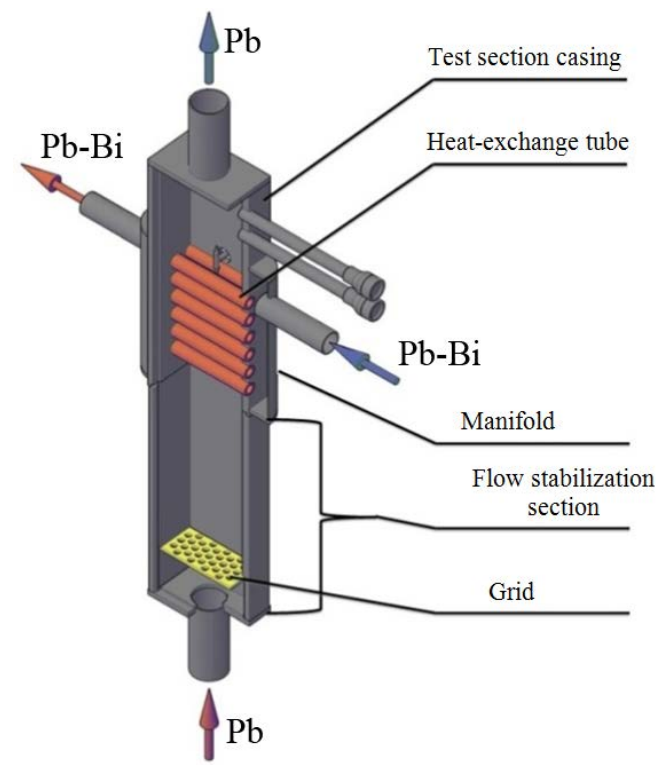

Figure 1. Experimental model diagram. 
Supplied to the test section, the lead passes through the grid designed for equalization of the velocity profile and then through a flow stabilization section $1000 \mathrm{~mm}$ in length. Then the lead coolant, flowing around the heat-exchange surface, transfers heat to the lead-bismuth eutectics pumped inside the heat-exchange tubes. The cooled lead is thereafter removed from the test section.

The temperature of the lead and the lead-bismuth at the inlet and outlet of the model is measured using submersible temperature transducers $1.5 \mathrm{~mm}$ in diameter. The temperature of the lead-bismuth eutectics inside the heat-exchange tubes is measured using micro-thermocouples installed in the central and outlet sections of the heat-exchange tubes.

These measurements make it possible to obtain integral heat-exchange characteristics that are in line with the averaged characteristics on the length of the heat-transferring surface. The heat-exchange characteristics at the initial section (stabilization section) have greater values than at the subsequent section of stabilized flow, so the obtained expressions produce overestimated values of these characteristics. In order to obtain more accurate results, this experimental research included measurements of local heat-exchange characteristics corresponding to the characteristics of the local heat-exchange surface area close to location of the flow temperature control means and the wall in contact with it.

To measure the temperature of the heat-transferring surface, chromel-alumel micro-thermocouples are installed on it in the central section at different angles toward the coolant incoming flow (Figure 2).

To measure the temperature on the "outer" and "inner" surfaces of the tubes, grooves $1 \mathrm{~mm}$ in width are cut in the sections under review, which grooves are metal-coated after laying and caulking of the micro-temperature transducer. The depth of the grooves on the "outer" surface of the tube equals $1 \mathrm{~mm}$ at the thickness of its wall of $3.0 \mathrm{~mm}$, and the depth of the grooves for transducers measuring the temperature of its "inner" surface equals $2.5 \mathrm{~mm}$. Metal-coating is carried out using the plasma-spraying technique in an inert-gas (argon) blanket. The applied coatings are processed flush with the primary surface. All the thermocouples have individual calibrating characteristics with a calibration accuracy of $\pm 0.2^{\circ} \mathrm{C}$.

The field of temperatures in the high-temperature lead coolant flow is measured by stationary micro-thermocouples installed in different sections throughout the height of the test section and by a thermoprobe installed in the gap section between the runs of the heat-transferring tubes.

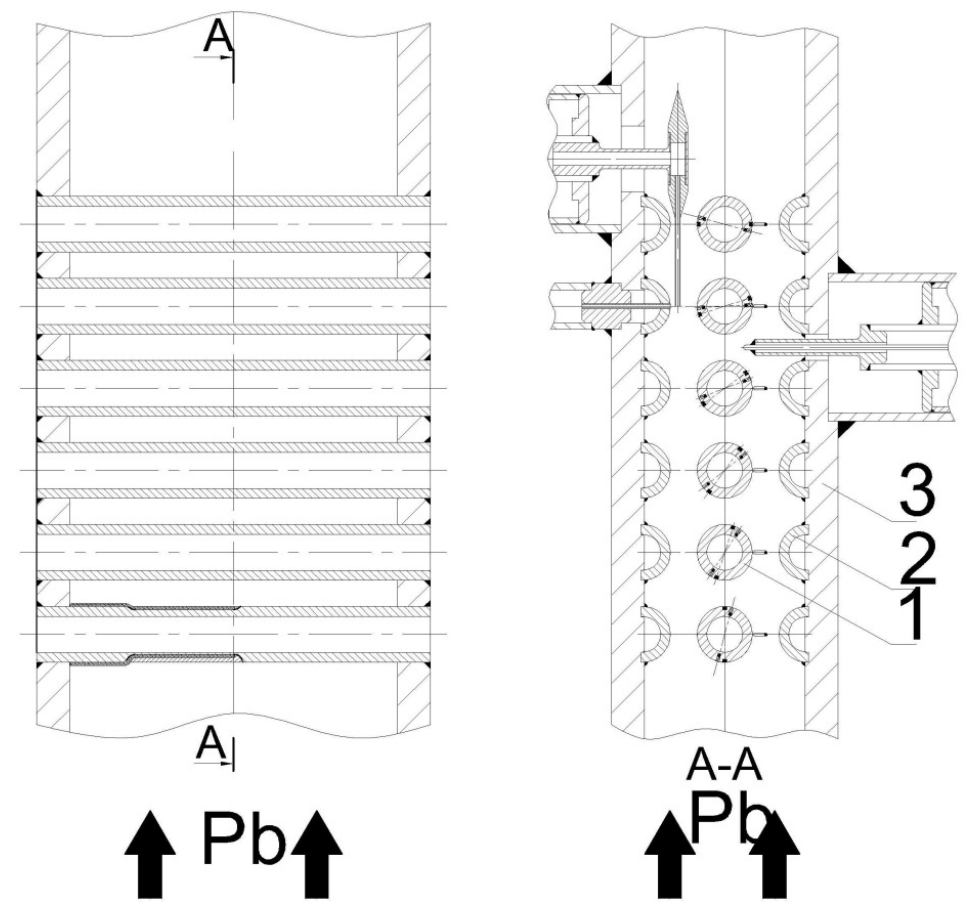

Figure 2. Diagram of micro-thermocouple embedding into test section: 1. Heat-exchange tube; 2 . Heat-exchange tube simulator; 3 . Test section casing; T-micro-thermocouple. 
The field of velocities across the gap section is measured by means of a velocity sensor (Figure 3).

The sensor allows for measuring the difference of potential Ppot and total Ptot pressure heads of the liquid metal flow. Based on the difference of the total and potential pressure heads, the axial component of the local velocity at a set flow point is calculated. The total pressure head is measured by means of a capillary (a tube having the inner diameter of $\mathrm{d}=1 \mathrm{~mm}$, the wall thickness of $\delta=0.25 \mathrm{~mm}$ ), its free end coming from the opposite direction to the lead coolant flow. Through the capillary and the tubing system, the liquid-metal coolant is supplied to a tank for measuring the total pressure head of the flow. The potential pressure head is measured through a hole in the test section wall. The free end of the capillary and the hole for measuring the potential pressure head in the wall are located in the same cross section of the test section tube. Through the hole for measuring the potential pressure head, the lead is supplied through the tubing system to a tank for measuring the potential pressure head.

The difference between the total and potential pressure heads during the performance of the experiment was measured as follows. The tanks for measuring the total and potential pressure heads were connected for gas. There was a gas pressure created in them, at which the coolant level was determined in each of the squeezing tanks. This done, the electrical contact bars were moved until contact of the bottom end with a free level of the liquid metal in the inner cavity of the tank, and as this took place, light signaling was triggered, and the position of the electrical contact bars was recorded. The measured difference of the fluid heads in the tanks was the dynamic velocity pressure Pd of the fluid at a current point-capillary bevel axis.

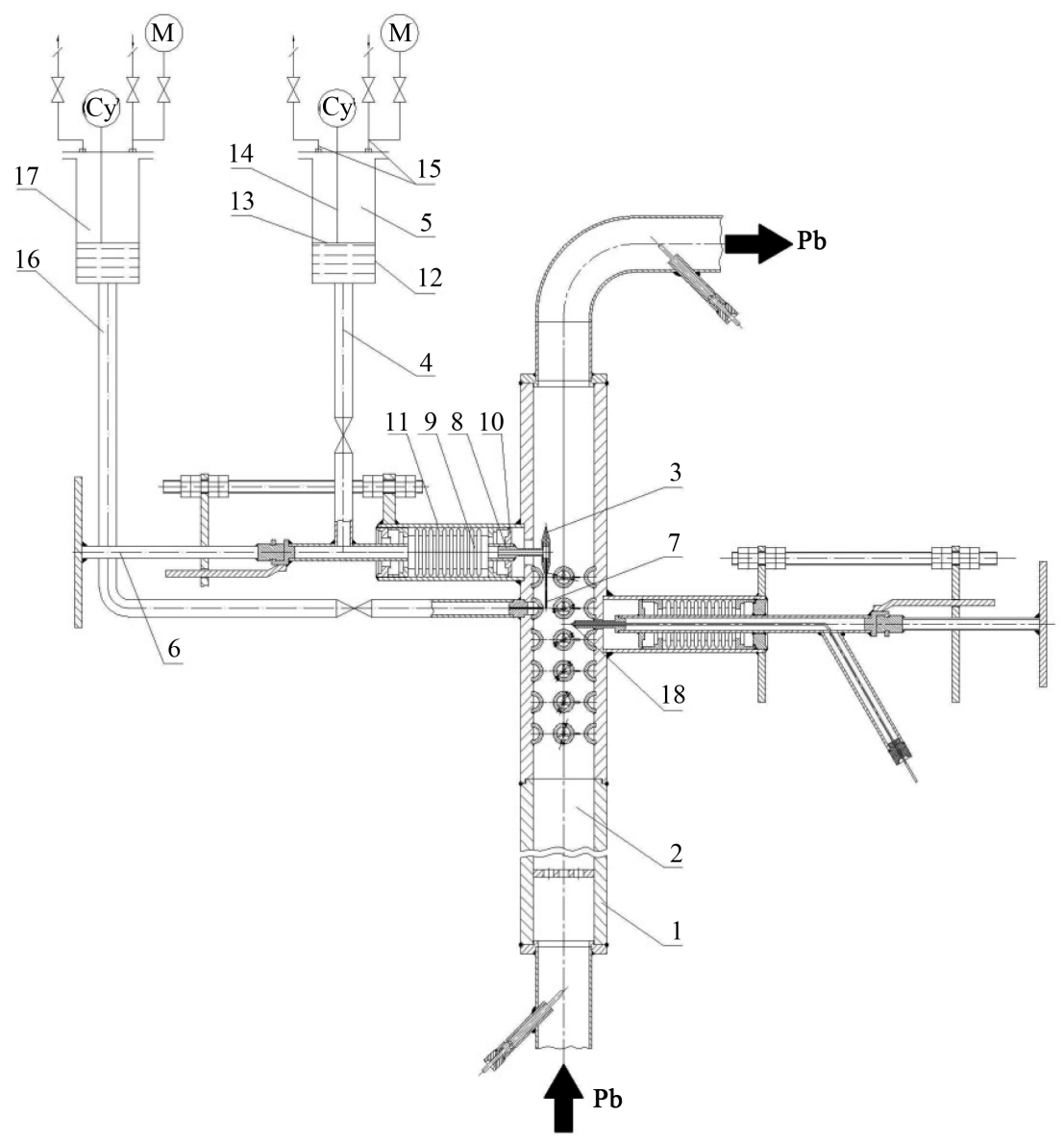

Figure 3. Velocity Sensor. 1. Test section casing; 2. Heavy liquid-metal coolant flow; 3. Deflector; 4. Total pressure head offtake channel; 5 . Total pressure head recording unit; 6. Transfer mechanism; 7. Capillary tube; 8 . Measuring probe; 9. Bellows; 10. Guide flange; 11. Bellows housing; 12. Pressure recording unit tank; 13. Free lead level; 14. Electriccontact level annunciator; 15. Gaseous system; 16. Static pressure head offtake channel; 17. Static pressure head recording unit; 18 . Thermoprobe. 
Data from primary instruments installed in test sections as well as from oxygen activity sensors and magnetic flow meters was collected and processed by the bench computer-aided system. The software makes it possible to: Obtain and process data with a time resolving power up to $0.3 \mathrm{sec}$, calculate thermophysical constants of materials and compute $\mathrm{Nu}$ and Pe numbers, display measurable parameters and calculation results on a real time basis, and save the data.

\section{Experimental Technique}

The experimental research of heat-exchange characteristics as well as temperature and velocity fields in a heavy liquid-metal coolant flow was carried out under the following operating parameters: lead coolant temperature $\mathrm{T}=$ $450^{\circ} \mathrm{C}-500^{\circ} \mathrm{C}$; controlled and regulated content of thermodynamically active oxygen impurity in alloy a $=10^{-5}$ $10^{0}$; lead flow through test section $\mathrm{Q}=3-6 \mathrm{~m}^{3} / \mathrm{h}$, which is equivalent of slip velocities in heat-exchange tubes $\mathrm{V}=0.4-0.8 \mathrm{~m} / \mathrm{s}$. The testing was conducted for instances of downward and horizontal flows of lead.

The testing procedure included the following stages:

-Development of methods for forming lead oxide impurity deposits on the loop and test section walls.

-Development of methods for removing lead oxide impurity deposits from the loop and test section walls.

-Experimental determination of the dependency relation $\mathrm{Nu}=\mathrm{f}(\mathrm{Pe})$ at the values of thermodynamically active oxygen in lead from $10^{-5}-10^{-4}$ to $10^{0}$ and during forming a layer of impurity deposits on the heat-transferring surface of the test section. Plotting of graphical and analytical dependencies $\mathrm{Nu}=f(\mathrm{Pe})$ at different contents of oxygen impurity in the coolant and in the loop.

-Experimental determination of velocity and temperature fields in the lead coolant flow.

-Experimental determination of thermohydraulic characteristics of a heavy liquid-metal coolant flow at controlled supply of gas to the coolant flow.

-Inspection of the bench and test section conditions.

Throughout all experiment stages, the bench was in a non-isothermal mode.

Each series of the research determined dependencies of heat-exchange characteristics in the heat offtake section in the following recurrent modes:

-With deoxidation of the lead coolant due to supply of "dry" hydrogen and with subsequent exposure of argon excessive pressure in the gaseous system;

-With oxidation of the lead coolant due to periodical supply of oxygen gas with subsequent exposure of argon excessive pressure in the gaseous system;

-Self-regulation of the loop in the inert-gas atmosphere;

-Purification with the use of two-phase coolant-gas mixtures (hydrogen, argon).

The results of these tests were compared with the previously performed tests, where the lead flow was moving "FROM BOTTOM TO TOP" [5]. The bench arrangement was in general unchanged, only position of the test section was varied in space. These manipulations were accomplished to reveal the heat-gravitational effect that could affect the resulting data.

\section{Experimental Results}

\subsection{Heat-Exchange Characteristics When Moving "FROM вотTOM TO TOP”}

The experimentally obtained dependencies $\mathrm{Nu}=\mathrm{f}(\mathrm{Pe})$ at different values of thermodynamically active oxygen $\left(100<\mathrm{a}<10^{-5}\right)$, Peclet number $(900<\mathrm{Pe}<3000)$ and angle of micro-thermocouples $\varphi$ relative to the face part of the heat-exchange tube are shown in Figure 4. The average values of $\mathrm{Nu}=\mathrm{f}(\mathrm{Pe})$ obtained by means of numerical integration in a circumferential direction of the heat-exchange tube at different values of thermodynamically active oxygen $\left(100<\mathrm{a}<10^{-5}\right)$ and Peclet numbers $(800<\mathrm{Pe}<3000)$ are shown in Figure 5.

The analysis shows that with an intense deoxidation of the coolant $\left(\mathrm{a} \approx 10^{-5}\right)$ by means of supplying dry hydrogen to the circulation loop, there occurs deterioration of the heat-exchange characteristics relative to similar parameters for a coolant having the content of thermodynamically active oxygen of $10^{-1}<\mathrm{a}<10^{-4}$. This difference may be explained by the change in the flow conditions of the heat-exchange surface due to variation in the characteristics of the surface wetting by the coolant (wetting angle) on account of partial damage (recovery) or alteration of the physical and chemical properties of the protective oxide coatings. As may be inferred from the consolidated graph of the average heat-exchange characteristics $\mathrm{Nu}=\mathrm{f}(\mathrm{Pe})$ (Figure 5), the heat-exchange cha- 

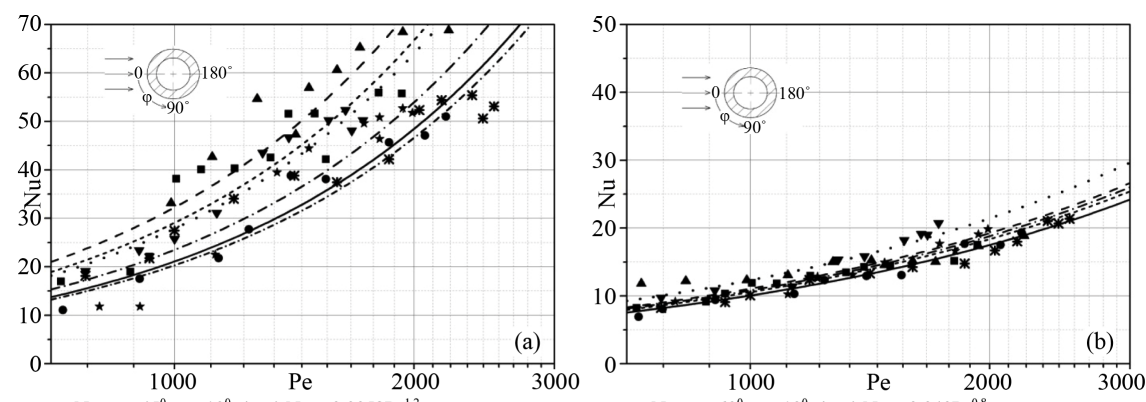

- $\mathrm{Nu}, \varphi=45^{0}, \mathrm{a}=10^{0} ;(-) \mathrm{Nu}=0.0053 \mathrm{Pe}^{1.2}$

- $\mathrm{Nu}, \varphi=45^{0}, \mathrm{a}=10^{-1} ;(--) \mathrm{Nu}=0.0081 \mathrm{Pe}^{1.2}$

- Nu, $\varphi=45^{0}, \mathrm{a}=10^{-2} ;(\cdots) \mathrm{Nu}=0.0070 \mathrm{Pe}^{1.2}$

- Nu, $\varphi=45^{0}, \mathrm{a}=10^{-3} ;(--) \mathrm{Nu}=0.0059 \mathrm{Pe}^{1.2}$

* $-\mathrm{Nu}, \varphi=45, \mathrm{a}=10^{-3} ;(-\ldots) \mathrm{Nu}=0.0073 \mathrm{Pe}^{1.2}$

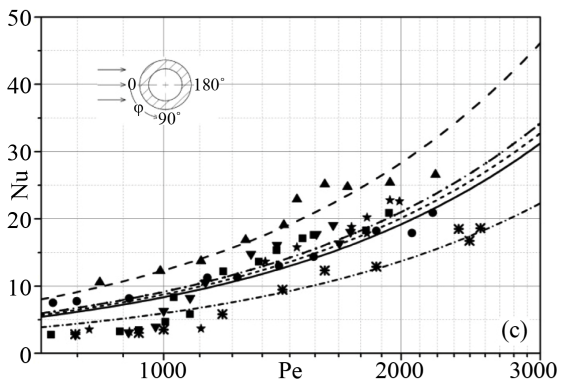

- $\mathrm{Nu}, \varphi=60^{\circ}, \mathrm{a}=10^{0} ;\left(\right.$ 一) $\mathrm{Nu}=0.040 \mathrm{Pe}^{0.8}$

- $\mathrm{Nu}, \varphi=60^{\circ}, \mathrm{a}=10^{-1} ;(--) \mathrm{Nu}=0.044 \mathrm{Pe}^{0.8}$

- $\mathrm{Nu}, \varphi=60^{\circ}, \mathrm{a}=10^{-2} ;(\cdots) \mathrm{Nu}=0.049 \mathrm{Pe}^{0.8}$

- Nu, $\varphi=60^{0}, a=10^{-3} \cdot(-\cdot-) \mathrm{Nu}=0.043 \mathrm{Pe}^{0.8}$

- Nu, $\varphi=60^{0}, a=10^{-4}$. $(--) \mathrm{Nu}=0.042 \mathrm{P}^{0.8}$

制

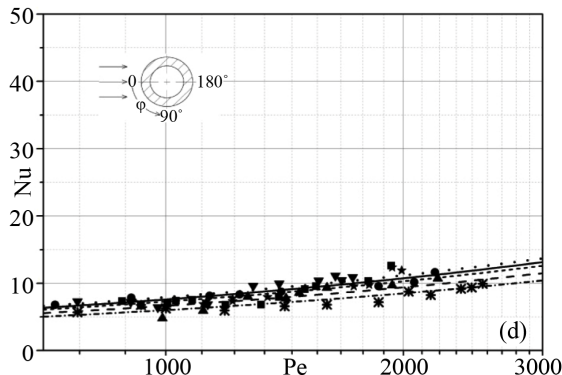

- $\mathrm{Nu}, \varphi=75^{0}, \mathrm{a}=10^{0} ;$ (一) $\mathrm{Nu}=0.0021 \mathrm{Pe}^{1.2}$

- $\mathrm{Nu}, \varphi=75^{0}, \mathrm{a}=10^{-1} ;(--) \mathrm{Nu}=0.0031 \mathrm{Pe}^{\mathrm{t}}$

- Nu, $\varphi=75^{0}, \mathrm{a}=10^{-2} ;(\cdots) \mathrm{Nu}=0.0023 \mathrm{Pe}^{1.2}$

$-\mathrm{Nu}, \varphi=75^{\circ}, \mathrm{a}=10^{-3} ;(-\cdot) \mathrm{Nu}=0.0023 \mathrm{Pe}^{1}$

- Nu, $\varphi=75, a=10 ;(\ldots) \mathrm{Nu}=0.0022 \mathrm{Pe}^{1}$

* $\mathrm{Nu}, \varphi=75^{0}, \mathrm{a}=10^{-5} ;(-\cdot) \mathrm{Nu}=0.0015 \mathrm{Pe}^{1.2}$

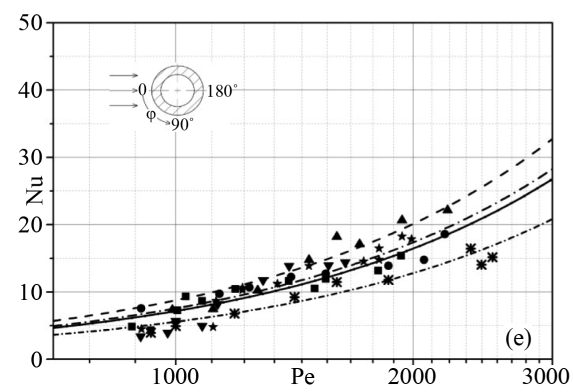

- - Nu, $\varphi=95^{0}, \mathrm{a}=10^{0} ;(-) \mathrm{Nu}=0.0018 \mathrm{Pe}^{1.2}$

- $\mathrm{Nu}, \varphi=95^{0}, \mathrm{a}=10^{-1} ;(--) \mathrm{Nu}=0.0022 \mathrm{Pe}^{1.2}$

V - Nu, $\varphi=95^{0}, \mathrm{a}=10^{-2} ;(\cdots) \mathrm{Nu}=0.0018 \mathrm{Pe}^{1.2}$

\ $\mathrm{Nu}, \varphi=95^{0}, \mathrm{a}=10^{-3} ;(-\cdot-) \mathrm{Nu}=0.0019 \mathrm{Pe}^{1.2}$

- $\mathrm{Nu}, \varphi=95^{0}, \mathrm{a}=10^{-4} ;(-\ldots) \mathrm{Nu}=0.0018 \mathrm{Pe}^{1.2}$

* $-\mathrm{Nu}, \varphi=95^{0}, \mathrm{a}=10^{-5} ;(-\cdot-) \mathrm{Nu}=0.0014 \mathrm{Pe}^{1.2}$

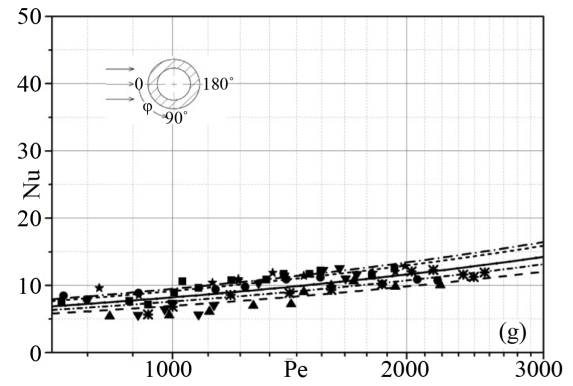

- $\mathrm{Nu}, \varphi=120^{\circ}, \mathrm{a}=10^{0} ;(-) \mathrm{Nu}=0.26 \mathrm{Pe}^{0.5}$

$-\mathrm{Nu}, \varphi=120^{\circ}, \mathrm{a}=10^{-1} ;(--) \mathrm{Nu}=0.22 \mathrm{Pe}^{0.5}$

$\mathrm{Nu}, \varphi=120^{0}, \mathrm{a}=10^{-2} ;(\cdots) \mathrm{Nu}=0.26 \mathrm{Pe}^{0 .}$

$-\mathrm{Nu}, \varphi=1200^{\circ}, \mathrm{a}=10^{-3},(-\mathrm{Nu}=0.26 \mathrm{Pe}$

$-\mathrm{Nu}, \varphi=120, \mathrm{a}=10^{-3} ;(-\cdot-) \mathrm{Nu}=0.30 \mathrm{Pe}$

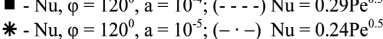

- $\mathrm{Nu}, \varphi=90^{\circ}, \mathrm{a}=10^{0} ;(-) \mathrm{Nu}=0.24 \mathrm{Pe}^{0.5}$;

- $\mathrm{Nu}, \varphi=90^{\circ}, \mathrm{a}=10^{-1} ;(--) \mathrm{Nu}=0.21 \mathrm{Pe}^{0.5}$

- $\mathrm{Nu}, \varphi=90^{\circ}, \mathrm{a}=10^{-2} ;(\cdots) \mathrm{Nu}=0.25 \mathrm{Pe}^{0.5}$

$-\mathrm{Nu}, \varphi=90^{\circ}, \mathrm{a}=10^{\circ} ;(-\cdot-) \mathrm{Nu}=0.24 \mathrm{Pe}$

- Nu, $\varphi=90^{\circ}, \mathrm{a}=10^{-5} ;(-\cdot) \mathrm{Nu}=0.19 \mathrm{Pe}^{0}$

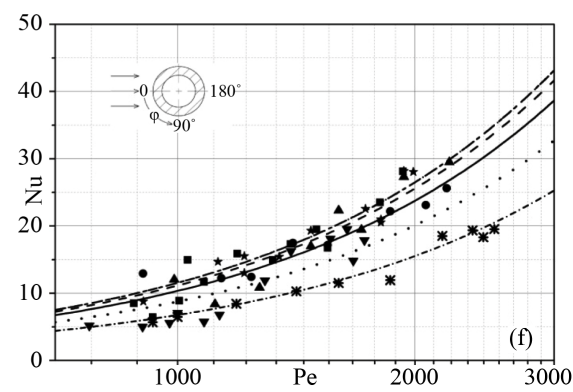

- $\mathrm{Nu}, \varphi=105^{0}, \mathrm{a}=10^{0} ;(-) \mathrm{Nu}=0.0026 \mathrm{Pe}^{1.2}$

$\triangle-\mathrm{Nu}, \varphi=105^{0}, \mathrm{a}=10^{-1} ;(--) \mathrm{Nu}=0.0028 \mathrm{Pe}^{1.2}$

V $\mathrm{Nu}, \varphi=105^{\circ}, \mathrm{a}=10^{-2} ;(\cdots) \mathrm{Nu}=0.0022 \mathrm{Pe}$

$-\mathrm{Nu}, \varphi=105^{0}, \mathrm{a}=10^{-3} ;(-\cdot) \mathrm{Nu}=0.0029 \mathrm{Pe}$

- $\mathrm{Nu}, \varphi=105^{0}, \mathrm{a}=10^{-4} ;(-\ldots) \mathrm{Nu}=0.0029 \mathrm{Pe}^{\mathrm{l}}$

* $\mathrm{Nu}, \varphi=105^{0}, \mathrm{a}=10^{-5} ;(-\cdot-) \mathrm{Nu}=0.0017 \mathrm{Pe}^{2}$

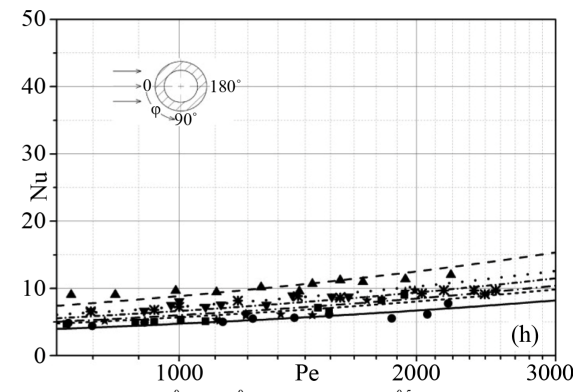

- $\mathrm{Nu}, \varphi=135^{0}, \mathrm{a}=10^{0} ;(-) \mathrm{Nu}=0.15 \mathrm{Pe}^{0.5}$

$-\mathrm{Nu}, \varphi=135^{\circ}, \mathrm{a}=10^{-1} ;(--) \mathrm{Nu}=0.28 \mathrm{Pe}^{0.5}$

$\checkmark \mathrm{Nu}, \varphi=135^{0}, \mathrm{a}=10^{-2} ;(\cdots) \mathrm{Nu}=0.23 \mathrm{Pe}^{0.5}$

$-N u, \varphi=135^{\circ}, a=10^{-3},(-), \quad N u=0.19 P^{0}$

$-\mathrm{Nu}, \varphi=135, \mathrm{a}=10^{-4},(-\cdot) \mathrm{Nu}=0.19 \mathrm{Pe}$

* $\mathrm{Nu}, \varphi=135^{\circ}, \mathrm{a}=10^{-5} ;(-\cdot) \mathrm{Nu}=0.21 \mathrm{Pe}^{0.5}$

Figure 4. Local heat-exchange characteristics. Consolidated graphs $\mathrm{Nu}=\mathrm{f}(\mathrm{Pe})$. 


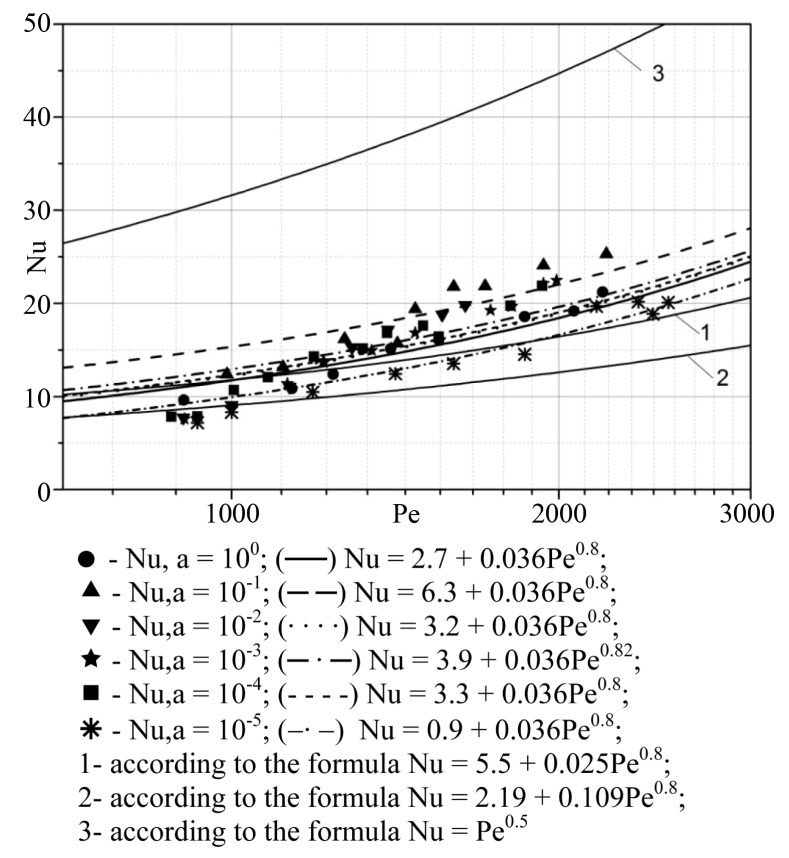

Figure 5. Integral heat-exchange characteristics. Consolidated graph $\mathrm{Nu}=\mathrm{f}(\mathrm{Pe})$.

racteristics, at fairly low thermodynamic activity of oxygen and in the context of potential wetting of the surface by the coolant $\left(\mathrm{a} \approx 10^{-5}\right)$, are close to the theoretical data for pure metals obtained by S. I. Sherbakov as a result of a numerical investigation for heat-exchange on the part of liquid metal while flowing around the tube bank of a coiled steam generator: $\mathrm{Nu}=5.5+0.025 \mathrm{Pe}^{0.8}$; where the constitutive parameters include the tube outer diameter and the liquid metal flow velocity in a narrow gap between the tubes.

This result once more proves the fact that with a significantly deoxidated coolant, conditions of the wall boundary area, characteristics of the flow and the surfaces of construction materials, the heat-exchange characteristics for lead are close to those for mercury and alkaline metals.

Introducing oxygen into the loop up to the values of thermodynamic activity of oxygen in lead $\left(10^{-1}<\right.$ a $<$ $10^{-4}$ ) consecutively resulted in the heat-exchange performance gain, which might result from formation of protective oxide coatings on the heat-exchange surface. Formation of oxide coatings leads to unwettability of the heat-exchange surface with the coolant and may also increase the surface roughness making it more well-developed.

With an unacceptably greater oxidation of the lead coolant $\left(\mathrm{a} \approx 10^{0}\right)$, there occurs a deterioration of the heatexchange characteristics. This difference may be accounted for by the fact that in the wall boundary area of a "cold" wall, there occurs a formation of impurity deposits due to impurity crystallization from the coolant in the coldest area of the loop, on account of thermal diffusion of finely-divided impurity particles coming to the areas with the maximum viscosity of the liquid-metal coolant and other processes. The impurity deposit layer on the heat-exchange surface has a greater thermal resistance deteriorating the heat-exchange characteristics.

Similar results of $\mathrm{Nu}=\mathrm{f}(\mathrm{Pe})$ were obtained at a horizontal lead flow.

\subsection{Temperature Profile Characteristics}

The dimensionless temperature profiles in a lead coolant flow measured in a cross section between the runs of heat-exchange tubes are shown in Figure 6. While plotting the graphs, the correlation $\Theta=\mathrm{T} / \mathrm{Tav}$ is taken as a relative temperature (where $\mathrm{T}$ is a temperature measured by a movable thermoprobe at a given flow point; Tav is the average temperature of the lead coolant flow measured by stationary thermocouples installed in narrow sections between the runs of heat-exchange tubes located before and after the thermoprobe; $\mathrm{S}$ is a current position of the thermoprobe).

It follows from the analysis of the temperature profiles that at low velocities of the coolant $(\mathrm{Pe}=400)$, the rear 


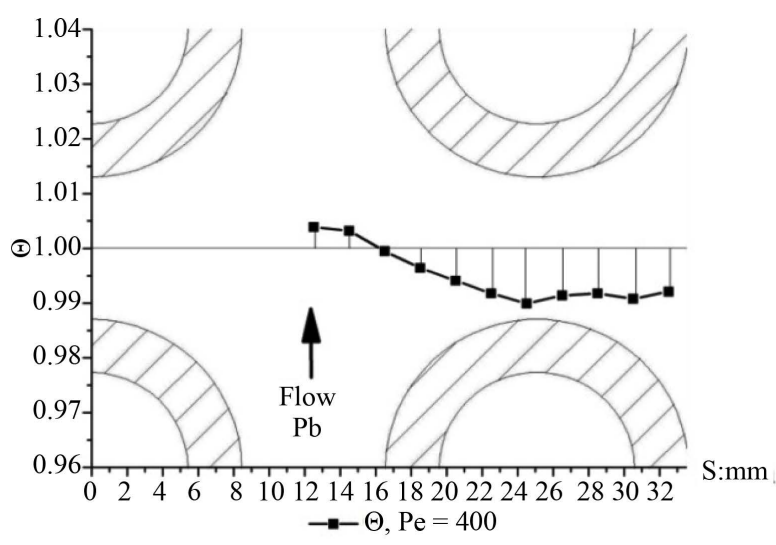

(a)

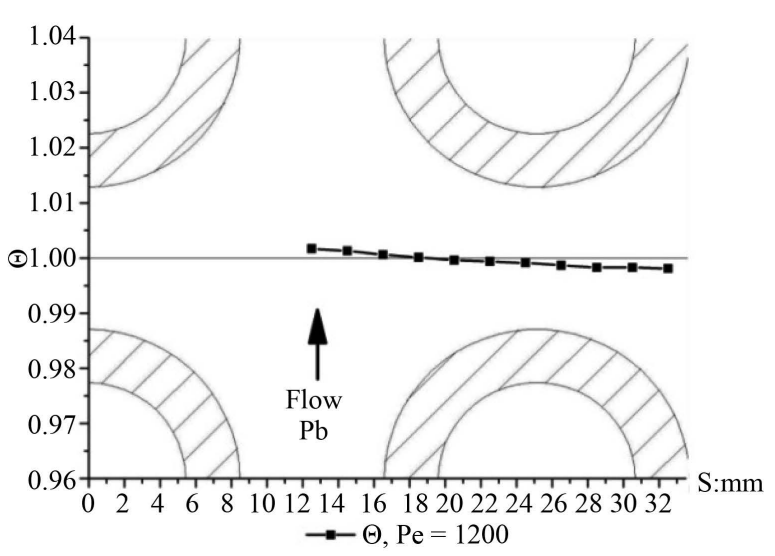

(c)

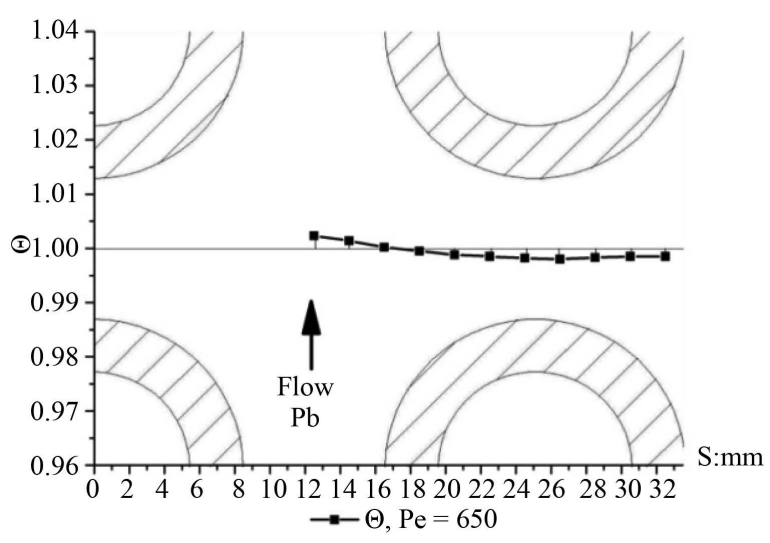

(b)

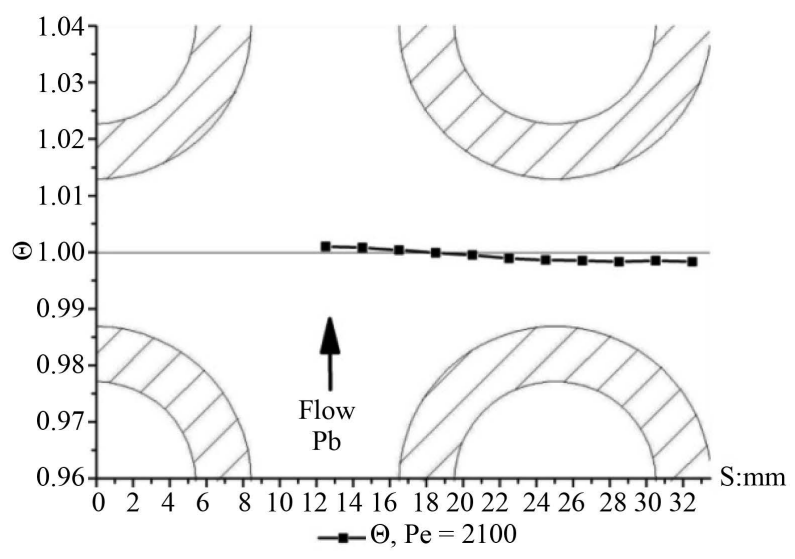

(d)

Figure 6. Dimensionless temperature profiles.

and front parts of the tubes include a zone having a lesser flow rate, which is proven by reduced temperature of the coolant. With an increase in the coolant flow velocity $(1200<\mathrm{Pe}<2100)$, the dimensionless temperature profile flattens, which points out to an increase in the intensity of the lead coolant mixing due to intensification of turbulent motion in the rear and front areas.

-At $\mathrm{Pe}=400$, the maximum difference between the thermoprobe temperature readings was $6.9^{\circ} \mathrm{C}$.

-At $\mathrm{Pe}=650$, the maximum difference between the thermoprobe temperature readings was $2.1^{\circ} \mathrm{C}$.

-At $\mathrm{Pe}=1200$, the maximum difference between the thermoprobe temperature readings was $1.7^{\circ} \mathrm{C}$.

-At $\mathrm{Pe}=2100$, the maximum difference between the thermoprobe temperature readings was $1.3^{\circ} \mathrm{C}$.

Consequently, any increase in the velocity of flowing around the heat-exchange surface significantly improves heat-exchange in the rear and front areas of the in-line tube.

Figure 7 shows similar dependencies but with a variable content of dissolved oxygen in the loop.

A reduction in the content of thermodynamically active oxygen impurity in an alloy also results in "flattening" (equalization) of the temperature field. This effect may be caused by a change in hydrodynamic peculiar properties of flowing around tubes due to variation of the wall boundary layer performance on the heat-exchange surfaces. In case of surface wetting with the coolant, there occurs an increase in the angle of separation from the tube wall with the result that the turbulent motion is intensified, and the temperature field is equalized in the rear part of the tube.

The experimentally obtained velocity fields at the lead coolant flowing in a narrow section between the runs of heat-exchange tubes are presented in the form of graphical dependencies $V=f(S)$ (where $V$ is the axial component of the lead coolant flow velocity; $S$ is the current position of the open end of the impact pressure probe of the velocity sensor) at different Re numbers (Figure 8).

The graph of velocity distribution according to a gap section has the appearance of a flattened W. The flat- 

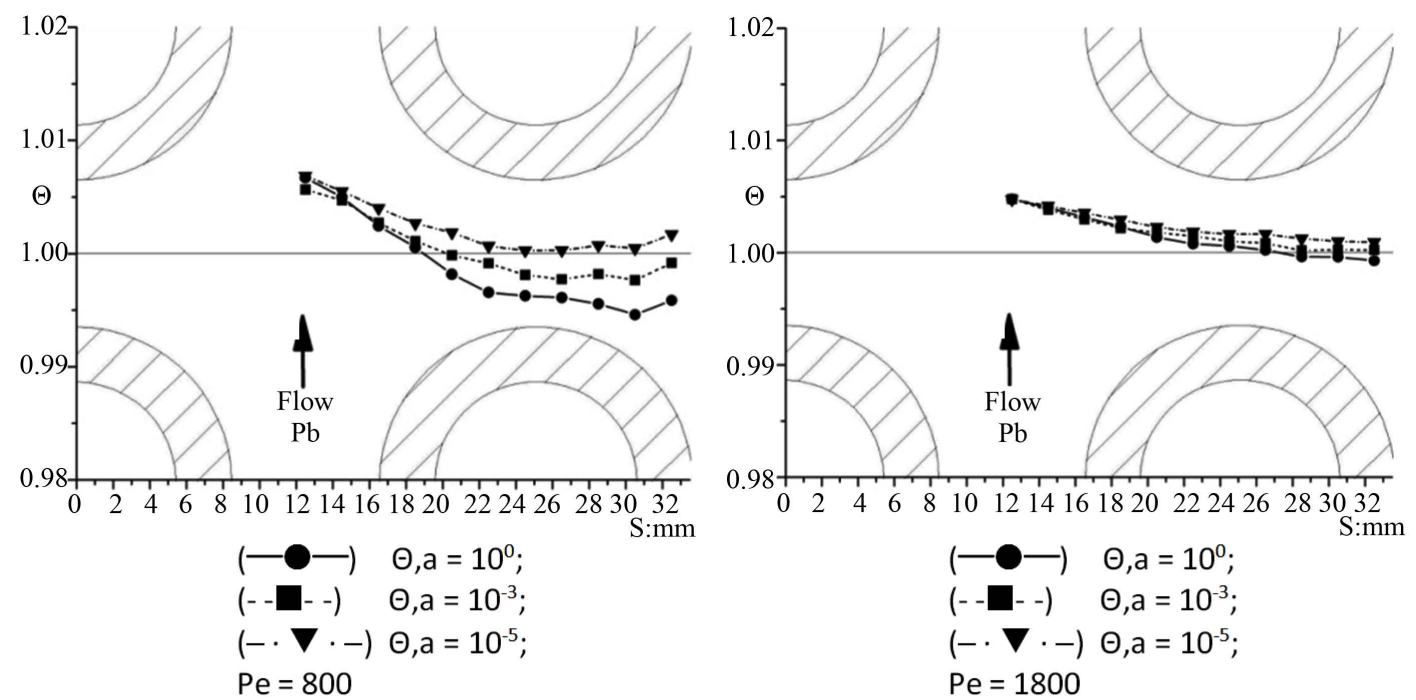

Figure 7. Dimensionless temperature profiles.
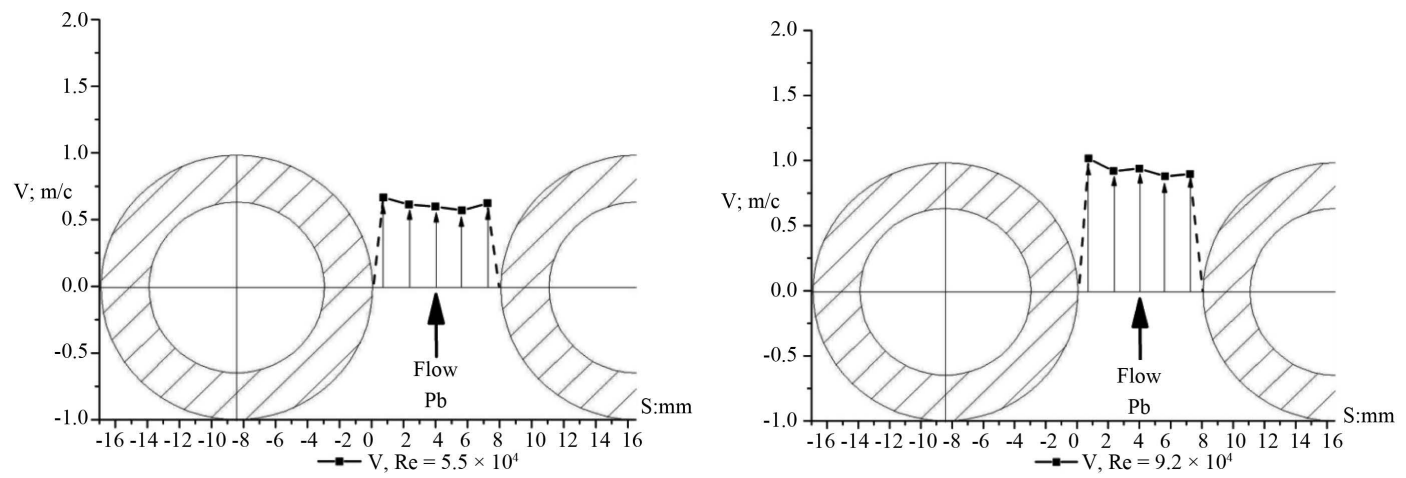

Figure 8. Dimensionless temperature profiles.

tened shape may be accounted for by the fact that the boundary layer has a very shallow thickness due to the surface unwettability with lead. As a result, the flow velocities near the wall and in the flow center differ in a minor way.

Formation of the velocity profile in the shape of $\mathrm{W}$ is probably due to the heat-gravitational effect arising in the lead coolant flow as a result of the lead temperature gradient throughout the height of the test section. Since the lead cools down while it is pumped through the test section in the direction from bottom to top, the heat-gravitational flow will have the opposite direction (from top to bottom). It is the overlapping of these flows that leads to formation of the $\mathrm{W}$-shaped velocity profile.

\subsection{Heat-Exchange Characteristics while Simulating Interloop Leakiness}

Experiments for determining heat-exchange characteristics were carried out by introducing gas (air, hydrogen) into the coolant flow with regulation of the coolant oxidizing potential.

The experimentally obtained dependencies of temperatures on the outer $\mathrm{T} 1$ and the inner T2 surfaces of the heat-exchange tube on the time $t$ at different gas flow rates are shown in Figure 9.

The analysis of the temperature graphs shows that with introducing hydrogen gas into the coolant flow, there occurs a sharp decrease in temperatures of the outer and inner heat-exchange surfaces within the range of the gas flow rate $\left(11.4 \mathrm{l} / \mathrm{h}<\mathrm{Q}_{\text {gas }}<186 \mathrm{l} / \mathrm{h}\right)$. Then the temperatures rise steeply, following which the process is repeated acquiring pulsation and a cyclical form with a fixed period of fluctuations $t_{k}=14.7 \mathrm{~s}$. The mean amplitude of the outer surface temperature fluctuations $\left(\mathrm{AT}_{1}=5^{\circ} \mathrm{C}\right)$ is greater than that of the inner surface $\left(\mathrm{AT}_{2}=3 \cdot 3^{\circ} \mathrm{C}\right)$. With termination of the gas supply, the temperature fluctuation amplitude reduces, where after stabilization of temper- 


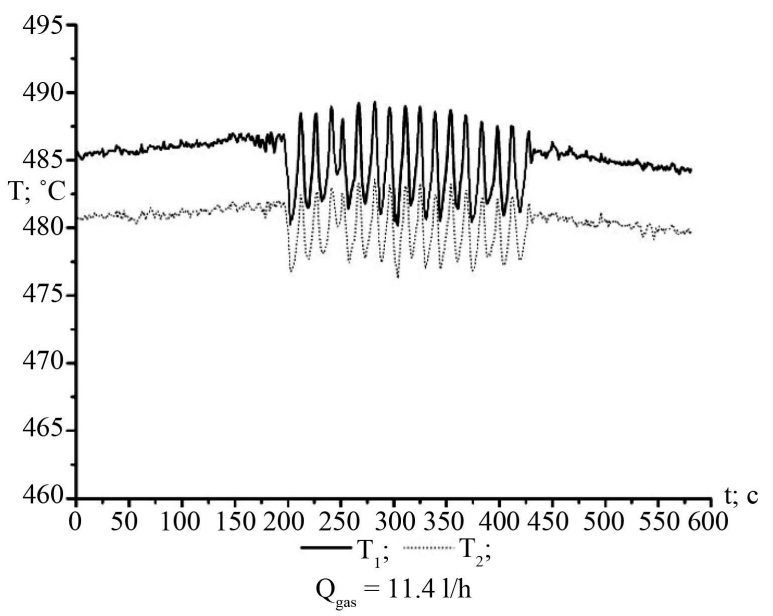

(a)

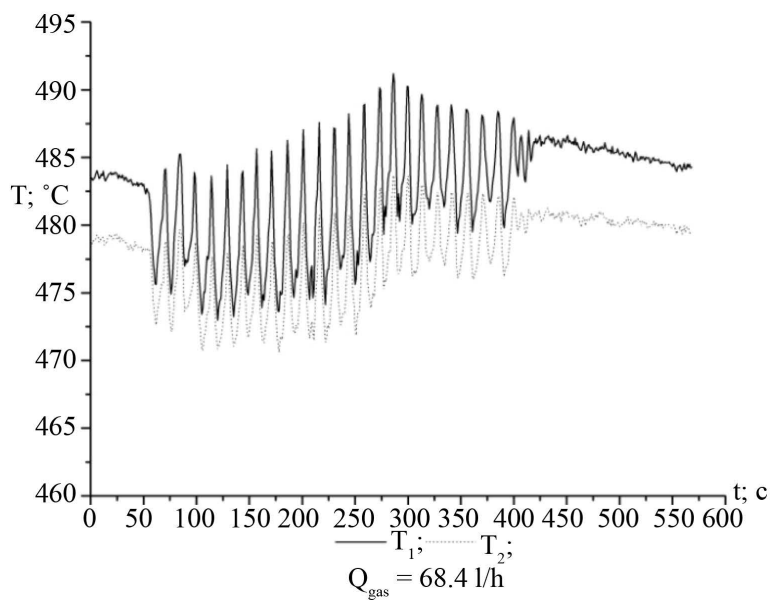

(c)

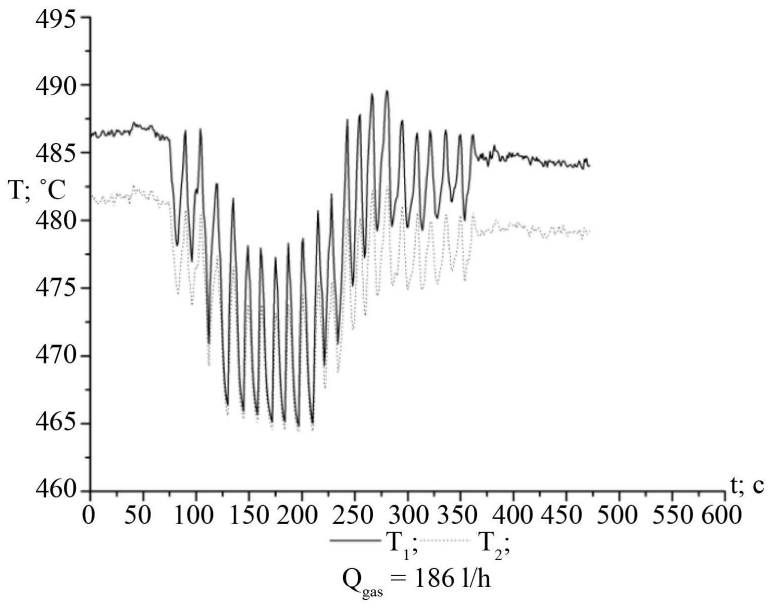

(e)

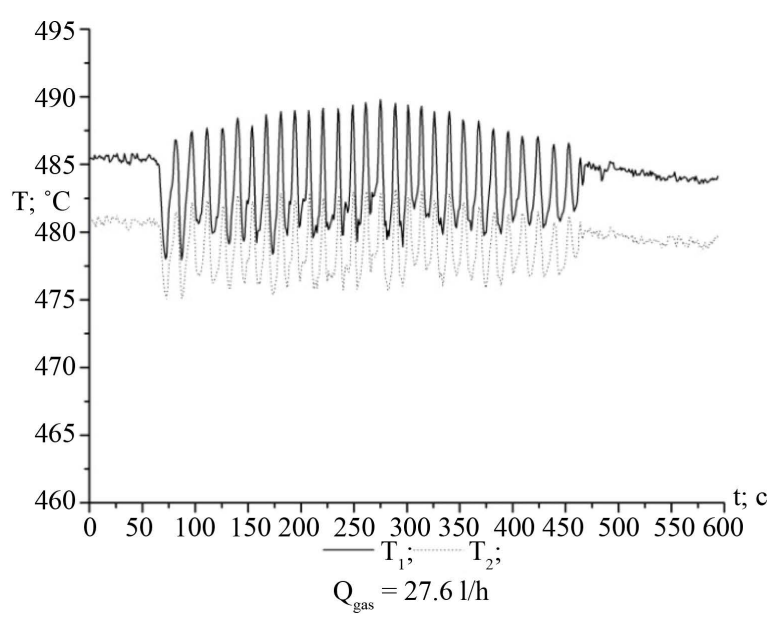

(b)

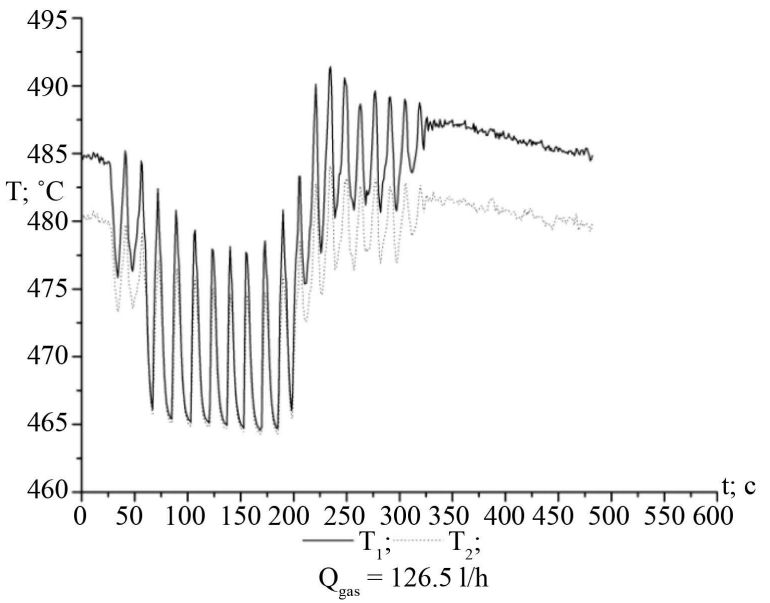

(d)

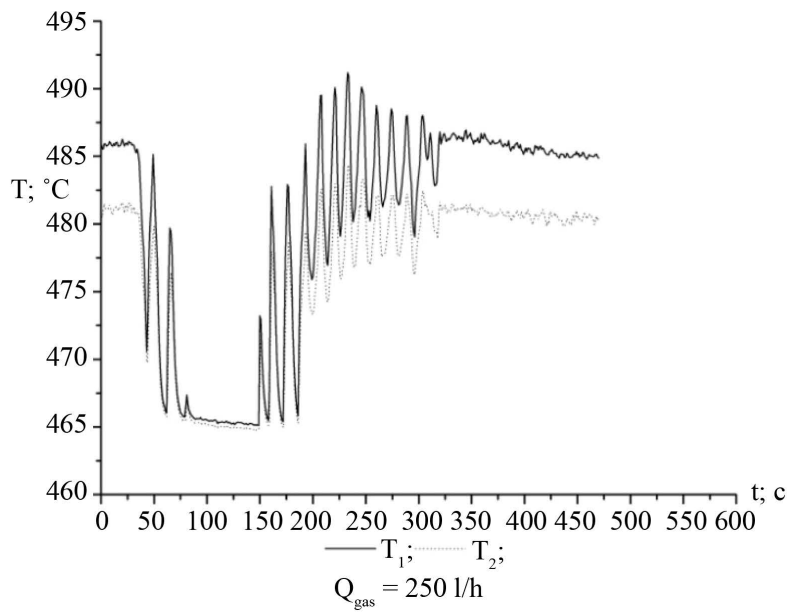

(f)

Figure 9. Graphs of heat-exchange surface temperature variation in time.

ature readings occurs.

With an increase in the gas flow rate up to $Q_{\text {gas }}=250 \mathrm{l} / \mathrm{h}$, there firstly occurs a temperature pulsation, then while continuing the gas supply, there occurs a loss of the temperature head in the wall, which is indicative of 
complete termination of heat-exchange through the tube surface. With termination of the gas supply to the coolant, temperature pulsations with the amplitude $\left(\mathrm{AT} 1=8^{\circ} \mathrm{C}\right.$; AT2 $=6^{\circ} \mathrm{C}$ ) and period of fluctuations $\mathrm{t}_{\mathrm{k}}=14.8 \mathrm{~s}$ start to make appearance and grow in the wall.

Such cyclical temperature fluctuations in the heat-exchange tube wall may, during continuous running, result in accumulation of thermal stresses in the wall and, as a consequence, in fatigue breakdown of the heat-exchange surface.

\section{Abstracts}

1) There has been detected a decrease in the angle of the lead coolant flow separation from the heat-exchange tube relative to the same parameter for a water coolant, which finally results in heat-exchange intensification.

2) An increase in the slip velocity in a tube bank also results in heat-exchange intensification due to strengthening of the turbulent motion in rear and front parts of tubes, and equalization of the temperature field along the channel section.

3) There has been detected an impact of the heat-gravitational effect on velocity profiles in the gap between in-line heat-exchange tubes.

4) It has been demonstrated that a steam generator leakage affects the thermohydraulic characteristics of a lead flow. It is estimated that continuous operation with a steam generator leakage may lead to fatigue breakdown of the heat-exchange surface.

5) A high content of thermodynamically active oxygen in a coolant $\left(\mathrm{a}>10^{-4}-10^{-5}\right)$ results in deterioration of heat-exchange performance due to variation of the boundary layer characteristics.

6) A reduction in the oxidizing potential of a coolant $\left(\mathrm{a} \sim 10^{-5}\right)$ deteriorates the heat-exchange characteristics.

7) Heat-exchange characteristics resulting from a low content of thermodynamically active oxygen in a coolant $\left(\mathrm{a} \sim 10^{-5}\right)$ are close to theoretical data obtained for instances of pure metal crossflow around tubes.

8) At heavy liquid-metal crossflow around tubes, there appear temperature irregularities and gradients along the perimeter of the tube as well as pulsations of the heat-exchange surface temperature in time caused by the flow inherent instability and a possible leakage in the steam generator. These factors should be considered during designing a tubing system of the BREST steam generator.

\section{Conclusion}

As a result of the conducted investigations, comprehensive experimental research of heat-exchange characteristics and peculiar properties of heavy liquid-metal coolant flowing around tubes has been carried out for the first time, and the dependencies $\mathrm{Nu}=\mathrm{f}(\mathrm{Pe})$ under a controlled and regulated content of thermodynamically active oxygen impurity $10^{-5}-10^{0}$ have been obtained. Temperature and velocity fields in in-line tube banks have been obtained, and the effect of supplying steam with a leakage in a steam generator or gas during its capture by a lead flow on the heat-exchange characteristics has been investigated as applied to the conditions of the BREST reactor installation.

\section{References}

[1] Beznosov, A.V., Novozhilova, O.O. and Savinov, S.Yu. (2009) Experimental Research of Flow Velocity of a Heavy Liquid-Metal Coolant. Nuclear Power, 106, 234-237.

[2] Beznosov, A.V., Novozhilova, O.O. and Savinov, S.Yu. (2008) Experimental Research of Heat-Exchange Processes and Temperature Profiles of a Heavy Liquid-Metal Coolant Flow. News of Higher Educational Establishments. Nuclear Power Industry, No. 3, 80-90.

[3] Beznosov, A.V., Novozhilova, O.O., Savinov, S.Yu., Antonenkov, M.A. and Yarmonov, M.V. (2010) Experimental Research of Axial Velocity of a Lead Coolant Flow in an Annular Gap with Different Oxidizing Potentials. Nuclear Power, 108, 173-177.

[4] Isachenko, V.P., Osipov, V.A. and Sukomel, A.S. (1975) Heat Transfer. Textbook for Higher Educational Establishments. 3rd Edition, Energia, Moscow, 222-231.

[5] Beznosov, A.V., Yarmonov, M.V. and Chernysh, A.S. (2013) Experimental Research of Heat-Exchange Characteristics at a Coolant Crossflow Moving "FROM BOTTOM TO TOP” under a Controlled and Regulated Content of Oxygen Impurity. Research Report, N. Novgorod. 
Scientific Research Publishing (SCIRP) is one of the largest Open Access journal publishers. It is currently publishing more than 200 open access, online, peer-reviewed journals covering a wide range of academic disciplines. SCIRP serves the worldwide academic communities and contributes to the progress and application of science with its publication.

Other selected journals from SCIRP are listed as below. Submit your manuscript to us via either submit@scirp.org or Online Submission Portal.
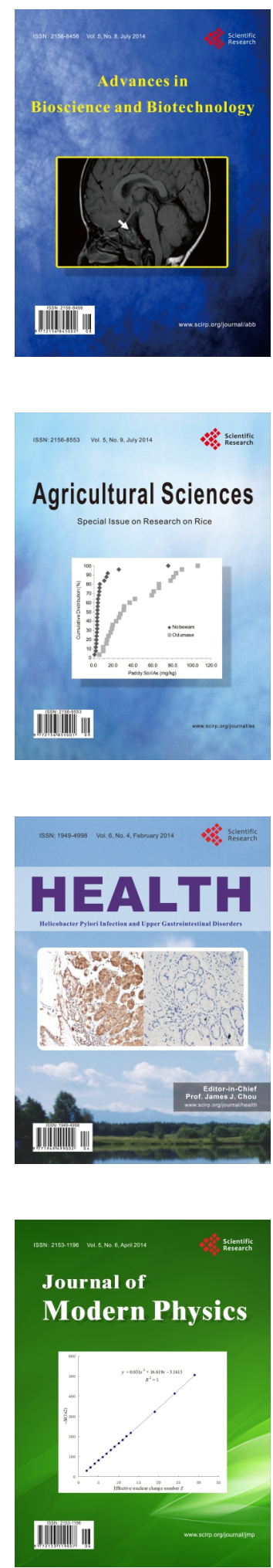
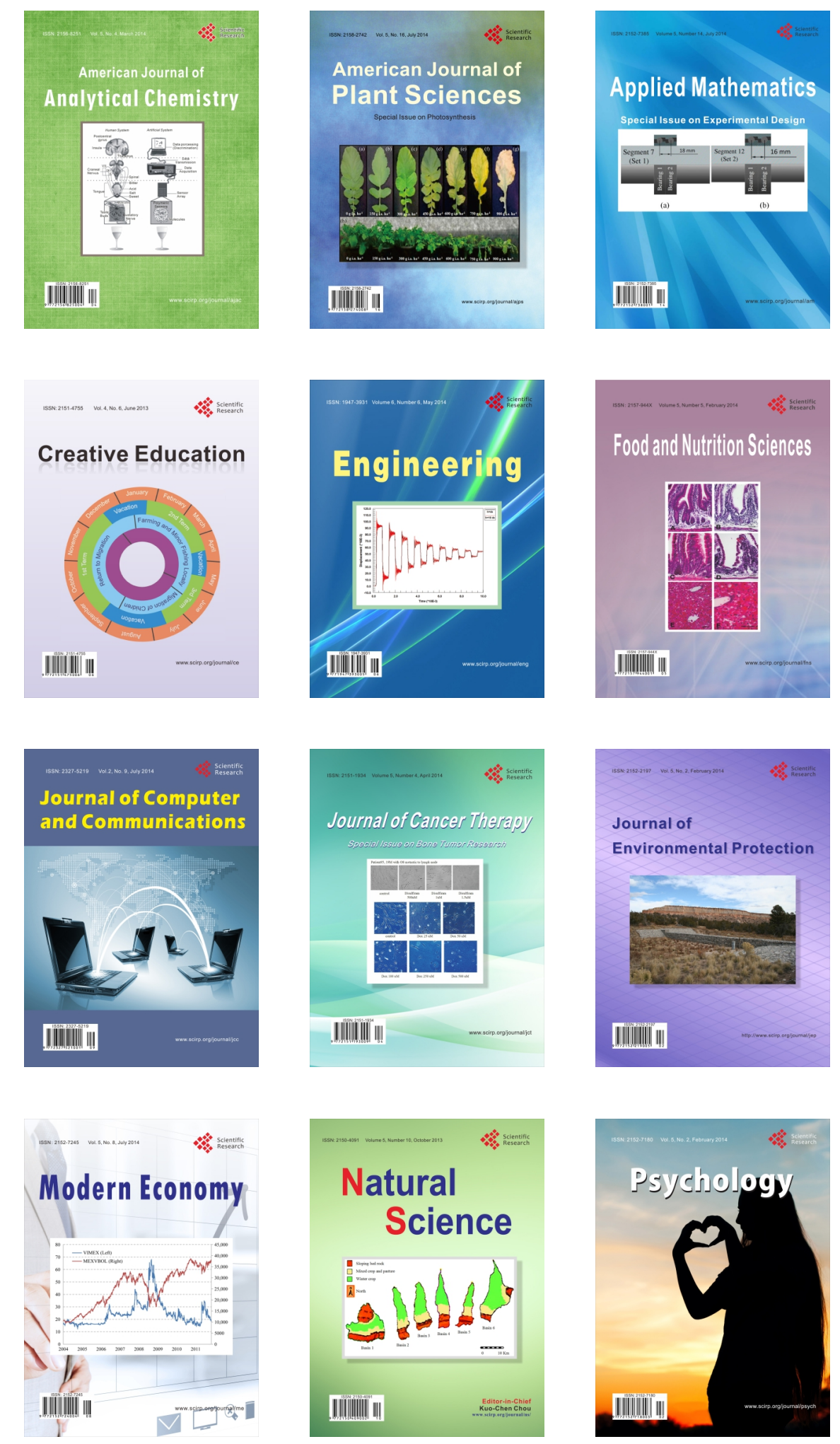